Solution $T$ was distinctly acid $(P h=4 \cdot 5)$, solution $\mathrm{J}$ was practically neutral $(\mathrm{Ph}=6.6)$, while solution $\mathrm{A}$ was distinctly alkaline $(\mathrm{Ph}=8.0)$. The erratic behavior of solution $A$ is probably due to its alkaline reaction.

Obviously calcium chloride is entirely unsuited for use in anti-freezing solutions in the cooling systems of motor vehicles in which aluminum or copper or both are in electrical contact with iron or steel. Rapid destruction, particularly of the aluminum parts, is to be expected. Actual experience has abundantly confirmed the results of the tests described. ${ }^{1}$

The writer desires to acknowledge with thanks the assistance of Mary Hull, F. W. Waterman, and A. C. Haebich in carrying out the details of the work described in this paper.

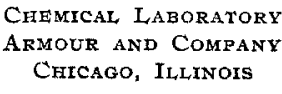

\section{A SIMPLE WEIGHING BURETTE}

By Donald W. MacArde

Received April 8, 1919

In many of the assays encountered in pharmaceutical work such as alkaloidal assay, a considerable degree of accuracy in titration is necessary. In order to avoid certain of the disadvantages of ordinary burettes, such as inaccuracy of bore, temperature variation, drainage, and difficulty of accurate reading, the writer has devised a simple weighing burette which obviates all corrections and allows nearly as rapid work as the ordinary style, with accuracy limited only by the sensitiveness of the end-point.

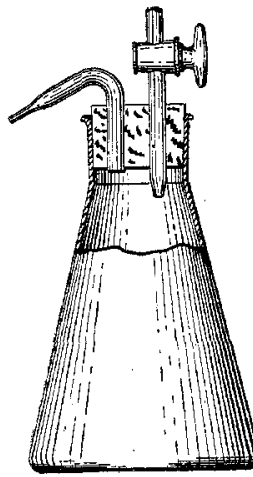

The sketch is practically selfexplanatory. The glass stopcock was taken from a broken burette. To use the burette, turn up with the cock closed, so that the capillary is over the titrating vessel, and allow the heat of the hand to force the standard solution into the capillary. Then when the cock is opened the liquid will flow freely, and there will be no danger of loss through the cock. When near the end-point, the $\operatorname{coc}^{1}$ may be closed and the solution forced in drops by the heat of the hand.

A predetermined quantity of solution cannot be delivered without repeated weighings, but a little practice will enable the user to estimate the desired quantity within a few per cent.

A roo cc. flask with rubber stopper, cock, and capillary, weighs about $40 \mathrm{~g}$.

\section{ANALYTrCat, AND Research DEPARTMENT \\ UNITED DRUg COMPANY \\ BOSTON, MASSACHUSETTS}

1 In addition to its corrosive nature, calcium chloride has another serious disadvantage, namely, the fairly good electrical conductivity of its solution. In the case of leaks or other accidents, short-circuiting of the ignition system may easily happen.

\section{A NEW FORM OF DISTILIING BULB}

By J. S. McHARGUE

Received Aptil 23, 1919

Fig. I represents a new form of distilling bulb and Fig. 2 indicates the method of constructing the bulb from sections of glass tubing of different sizes. The $\mathrm{T}$ is made by sealing a section of tubing ro $\mathrm{mm}$. inside diameter and $45 \mathrm{~mm}$. long on to a section $16 \mathrm{~mm}$. inside diameter and $\mathrm{r} 20 \mathrm{~mm}$. long. A drain hole 5 $\mathrm{mm}$. in diameter is blown out on opposite sides of the stem of the $T, I_{5} \mathrm{~mm}$. from the arms and directly beneath them.

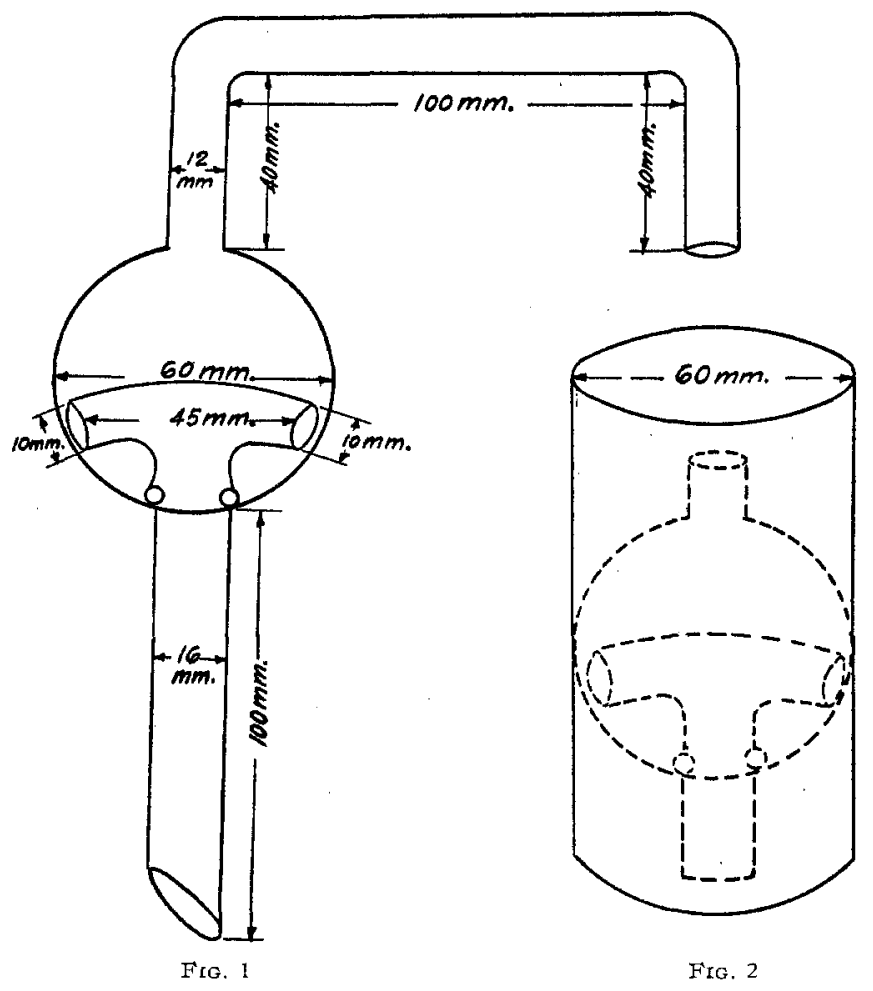

A section of glass tubing $60 \mathrm{~mm}$. inside diameter and with walls $\mathrm{r} .5 \mathrm{~mm}$. thick is drawn off and blown out to a uniform thickness and in the shape of a symmetrical dome at one end. A hole of sufficient size to admit the stem of the T-tube is blown out at the apex of the dome. The stem of the $T$ is inserted through this hole until the lower edges of the drain holes are opposite the rim of the hole in the large tube, and the two pieces sealed together at this point. The opposite end of the large tube is drawn off and blown out in such a way as to complete a symmetrical bulb of uniform thickness and $60 \mathrm{~mm}$. in diameter. After blowing a hole of the proper size at a point on the bulb opposite the one made for the stem of the $T$, a tube of $12 \mathrm{~mm}$. inside diameter is sealed on to make connection with a condenser tube. The form into which this tube is to be bent may vary, depending upon the most convenient manner of connecting a distilling flask to different types of condensers. In making the first bend in this tube above the bulb it is desirable that it be made in the direction that will preserve a right and left symmetry with respect to the arms of the $T$ within the bulb. 